\section{(O) OPEN ACCESS}

\title{
The genetic contribution to severe post-traumatic osteoarthritis
}

\author{
Ana M Valdes, ${ }^{1,2}$ Sally A Doherty, ${ }_{1}^{1}$ Kenneth R Muir ${ }^{3,4}$ Margaret Wheeler, ${ }^{1}$ \\ Rose A Maciewicz, ${ }^{5}$ Weiya Zhang, ${ }^{1}$ Michael Doherty ${ }^{1}$
}

\begin{abstract}
Handling editor Tore K Kvien
- Additional material is published online only. To view please visit the journal online (http://dx.doi.org/10.1136/ annrheumdis-2012-202562).

${ }^{1}$ Academic Rheumatology, Nottingham City Hospital, Nottingham, UK

${ }^{2}$ Department of Twin Research \& Genetic Epidemiology, King's College London, St Thomas' Hospital, London, UK

${ }^{3}$ Health Sciences Research Institute, Warwick Medical School, University of Warwick, Coventry, UK

${ }^{4}$ Institute of Population Health, University of Manchester, Manchester, UK

${ }^{5}$ Respiratory \& Inflammation Research Area, AstraZeneca, Charnwood R\&D, Loughborough, Leicestershire, UK
\end{abstract}

\section{Correspondence to} Dr Ana M Valdes, Department of Twin Research \& Genetic Epidemiology, Kings College London, St Thomas Hospital campus, London SE1 7EH, UK; ana.valdes@kcl.ac.uk

Received 24 August 2012 Revised 6 December 2012 Accepted 29 December 2012 Published Online First 26 January 2013

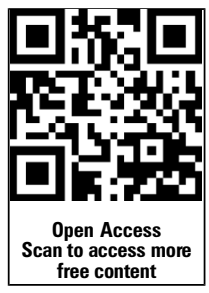

\footnotetext{
To cite: Valdes AM, Doherty SA, Muir KR, et al. Ann Rheum Dis 2013;72:1687-1690.
}

\section{ABSTRACT}

Objective to compare the combined role of genetic variants loci associated with risk of knee or hip osteoarthritis (OA) in post-traumatic (PT) and nontraumatic (NT) cases of clinically severe OA leading to total joint replacement.

Methods A total of 1590 controls, 2168 total knee replacement (TKR) cases (33.2\% PT) and 1567 total hip replacement (THR) cases (8.7\% PT) from 2 UK cohorts were genotyped for 12 variants previously reported to be reproducibly associated with risk of knee or hip OA. A genetic risk score was generated and the association with PT and NT TKR and THR was assessed adjusting for covariates. Results For THR, each additional genetic risk variant conferred lower risk among PT cases $(\mathrm{OR}=1.07,95 \% \mathrm{Cl}$ 0.96 to $1.19 ; p=0.24)$ than NT cases (OR $1.11,95 \% \mathrm{Cl}$ 1.06 to $1.17 ; p=1.55 \times 10^{-5}$ ). In contrast, for TKR, each risk variant conferred slightly higher risk among PT cases (OR 1.12, 95\% Cl 1.07 to $1.19 ; p=1.82 \times 10^{-5}$ ) than among NT cases (OR 1.08, 95\% Cl 1.03 to 1.1; $\mathrm{p}=0.00063$ ).

Conclusions Based on the variants reported to date PT TKR cases have at least as high a genetic contribution as NT cases.

\section{INTRODUCTION}

Large joint osteoarthritis (OA) is a common complex disorder with multiple genetic, constitutional and environmental risk factors and marked variability in phenotype. ${ }^{12}$

OA is divided into 'primary' OA, considered to result mainly from genetic and constitutional factors, and 'secondary' OA when there is an obvious cause of joint insult. ${ }^{3}$ A long-recognised risk factor for OA is direct joint injury, such as a subchondral fracture, meniscectomy, anterior cruciate tear or a deforming tibial or femoral fracture that results in poor alignment or leg length shortening. ${ }^{45}$ An estimated $12 \%$ of symptomatic OA may be attributed to a post-traumatic (PT) cause $^{6}$ and differences in radiographic patterns have been reported between primary and PT knee OA cases. ${ }^{7}$ However, two studies that examined the relationship between hand OA and the risk of developing knee OA following meniscectomy found that the presence of hand $\mathrm{OA}$ associated with a higher frequency and radiographic severity of post-meniscectomy $\mathrm{OA},{ }^{8} 9$ demonstrating that development of OA following a meniscal tear and subsequent surgery are not necessarily of secondary origin.

Genetic factors are known to influence risk of hip OA, knee OA and generalised OA (see Valdes and Spector $\left.{ }^{10}\right)$. Recent genetic association studies have identified a number of genetic variants associated with knee or hip OA or with severe large joint OA leading to total joint arthroplasty. ${ }^{11-15}$ To date, 12 independent variants have been reported to be associated with risk of hip or knee OA or related traits with a statistical significance level of $\mathrm{p}<1 \times 10^{-7}$ with (table 1 ).

The aim of this study was to examine whether PT OA might have a lower genetic contribution than non-traumatic (NT) idiopathic large joint OA. We investigated the combined role of the published OA-risk genetic variants in two case control studies from the UK focusing on severe OA leading to total knee replacement (TKR) and total hip replacement (THR).

\section{PATIENTS AND METHODS \\ Study cohorts}

THR and TKR cases were recruited from two casecontrol studies in Nottingham, UK: the Nottingham OA Case-Control and the Genetics of Osteoarthritis and Lifestyle (GOAL) study. Controls were obtained from both these studies.

\section{PT OA definition}

PT THR was defined as THR in the presence of hip injury and PT TKR as TKR in the presence of knee injury as described in the online supplementary methods section.

\section{Laboratory methods}

Genomic DNA was extracted from peripheral blood leukocytes of affected individuals and controls using standard protocols. Genotyping was carried out by Kbioscience Ltd, Hertfordshire, UK. Single nucleotide polymorphisms (SNPs) were genotyped using the Kompetitive Allele Specific PCR (KASPar) chemistry.

\section{Statistical analysis}

Genetic score

The sum of risk alleles (which can take values 0,1 or 2 for each variant) as defined in table 1 over all variants was computed for each study participant. Individuals with more than 1 missing genotype for all 12 variants were excluded, otherwise the genotype was imputed using the allele frequency in the population.

Logistic regressions using TKR or THR as outcomes and including age, gender, (BMI) and knee genetic risk score (for TKR) or hip genetic risk score (for THR) were performed. Analyses were 
Table 1 Genetic variants used to generate the genetic risk score

\begin{tabular}{|c|c|c|c|c|c|c|c|c|c|}
\hline Gene & SNP & $\begin{array}{l}\text { DNA } \\
\text { change }\end{array}$ & Reference & Trait associated & $\begin{array}{l}p \text { Value in } \\
\text { Caucasians }\end{array}$ & $\begin{array}{l}\text { RAF controls } \\
(\%)\end{array}$ & $\begin{array}{l}\text { Risk } \\
\text { allele }\end{array}$ & $\begin{array}{l}\text { Hip } \\
\text { gene }\end{array}$ & $\begin{array}{l}\text { Knee } \\
\text { gene }\end{array}$ \\
\hline GDF5 & rs143383 & $\mathrm{T} / \mathrm{C}$ & Valdes et $a l^{11}$ & Knee OA & $8 \times 10^{-9}$ & 61.9 & $\mathrm{~T}$ & - & + \\
\hline $\operatorname{COG5}{ }^{*}$ & rs4730250 & $\mathrm{A} / \mathrm{G}$ & Evangelou et $a l^{12}$ & Knee OA & $9 \times 10^{-9}$ & 19.3 & G & - & + \\
\hline MCFL2 & rs11842874 & $\mathrm{A} / \mathrm{G}$ & Day-Williams et $a l^{13}$ & Hip or knee $\mathrm{OA}$ & $9.2 \times 10^{-9}$ & 91.5 & $A$ & + & + \\
\hline PTHLH ${ }^{*}$ & rs10492367 & $\mathrm{A} / \mathrm{C}$ & $\operatorname{arcOGEN}^{14}$ & Hip OA & $1.5 \times 10^{-8}$ & 21.0 & A & + & - \\
\hline SUPT3H & rs10948172 & $\mathrm{G} / \mathrm{A}$ & $\operatorname{arcOGEN}^{14}$ & Hip or knee $\mathrm{OA}$ in men & $7.9 \times 10^{-8}$ & 28.6 & G & + & + \\
\hline TP63 & rs12107036 & $\mathrm{A} / \mathrm{G}$ & $\operatorname{arcOGEN}^{14}$ & TKR in women & $6.7 \times 10^{-8}$ & 53.6 & G & - & + \\
\hline FILIP1* & rs9350591 & $\mathrm{C} / \mathrm{T}$ & $\operatorname{arcOGEN}^{14}$ & THR & $2.42 \times 10^{-9}$ & 10.9 & $\mathrm{~T}$ & + & - \\
\hline GLN3* & rs11177 & $\mathrm{A} / \mathrm{G}$ & $\operatorname{arcOGEN}^{14}$ & Hip or knee $\mathrm{OA}$ & $7.24 \times 10^{-11}$ & 39.0 & A & + & + \\
\hline DOT1L & rs12982744 & $\mathrm{C} / \mathrm{G}$ & $\begin{array}{l}\text { Castaño-Betancourt } \\
\text { et } a l^{15}\end{array}$ & $\begin{array}{l}\text { Minimum joint space } \\
\text { widtht }\end{array}$ & $1.1 \times 10^{-11}$ & 60.2 & G & + & - \\
\hline ASTN2 & rs4836732 & $\mathrm{C} / \mathrm{T}$ & $\operatorname{arcOGEN}^{14}$ & THR & $6.1 \times 10^{-10}$ & 49.7 & $\mathrm{C}$ & + & - \\
\hline FTO & rs8044769 & $\mathrm{C} / \mathrm{T}$ & $\operatorname{arcOGEN}{ }^{14}$ & TKR in women & $6.8 \times 10^{-8}$ & 51.3 & $\mathrm{C}$ & + & + \\
\hline CHST11 & rs835487 & $\mathrm{A} / \mathrm{G}$ & $\operatorname{arcOGEN}{ }^{14}$ & THR & $1.6 \times 10^{-8}$ & 34.0 & G & + & - \\
\hline
\end{tabular}

carried out including all TKR (or THR) cases, only PT cases (PT-TKR or PT-THR) and only NT cases (NT-TKR or NT-THR). Results are reported as OR and corresponding 95\% CI for the GOAL and Nottingham cohorts separately. ORs were also meta-analysed for both cohorts using a fixed effects analysis. Analyses were performed using R V.2.13.1 (http://www.r-project. org/).

\section{RESULTS}

The list of variants investigated in this study is shown in table 1 along with the best-reported $\mathrm{p}$ value in the literature. The role of injury as a risk factor was assessed in the GOAL study where history of trauma was recorded for cases and controls. After adjustment for age, sex and BMI the risk estimates found were $\mathrm{OR}=3.27$, (95\% CI 2.51 to $4.25 ; \mathrm{p}<1.1 \times 10(-18))$ for TKR and $\mathrm{OR}=5.08$ (95\% CI 3.05 to $8.47 ; \mathrm{p}<4.2 \times 10(-10))$ for THR. The combined genetic and descriptive statistics risks in each cohort are shown in table 2 . These factors were analysed in each cohort to assess their role in defining risk of THR and TKR following trauma or in the absence of injury.

The mean of each of these risk factors stratified by injury status shows, as expected, a significantly younger age and a higher proportion of men in the post-trauma category (see online supplementary table S1).

The knee genetic risk score for TKR and the hip genetic risk score for THR are both significantly related to risk of total joint replacement (table 3). The average OR contributed by each additional variant carried is similar to those reported in the studies that identified these genetic variants (1.11 for hip OA risk variants and 1.09 for knee OA risk). Age and sex contribute differently to risk of PT-TKR and NT-TKR (see online supplementary table S1). We did not observe a significant difference in the risk conferred by knee genetic risk factors, but the OR is slightly higher for PT-TKR cases $(\mathrm{OR}=1.12)$ than for non-traumatic cases $(\mathrm{OR}=1.08)$. For THR only the gender composition is significantly different between NT and PT cases (see online supplementary table S1). The genetic risk conferred does not achieve statistical significance among PT-THR cases and is lower $(\mathrm{OR}=1.07)$ than among NT-THR cases $(\mathrm{OR}=1.11)$ where it is highly significant. Results were also computed excluding individuals with missing genotypes (see online supplementary table S2) and are very similar to those using imputed genotypes for missing data.

\section{DISCUSSION}

In this study we report for the first time the role of genetic factors in PT clinically severe OA requiring total joint replacement and compare it to the role that these same genetic factors play among 'primary' cases. Our hypothesis was that primary cases would carry a larger number of genetic risk variants than PT OA cases. However, the OR estimates for hip and knee risk scores are not significantly different between PT and NT subjects. Among TKR cases PT cases appear to carry a nonsignificantly larger proportion of risk variants. Among THR cases a lower contribution of genetic risk factors was seen in PT cases that did not achieve statistical significance.

Table 2 Descriptive statistics in the two study cohorts

\begin{tabular}{llll}
\hline Factor & Controls & TKR & THR \\
\hline Nottingham case control, n: & 711 & 1305 & 629 \\
Female, \% & $57.0 \%$ & $55.2 \%$ & $57.9 \%$ \\
Age (SD) & $66.29(8.97)$ & $69.75(9.21)$ & $70.39(8.75)$ \\
BMI (SD) & $26.57(3.93)$ & $30.15(5.61)$ & $28.83(4.88)$ \\
Knee gene score (SD) & $6.88(1.62)$ & $7.17(1.68)$ & $6.90(1.74)$ \\
Hip gene score (SD) & $6.14(1.62)$ & $6.10(1.57)$ & $6.41(1.69)$ \\
Hip injury, \% & NA & $5.2 \%$ & $10.8 \%$ \\
Knee injury, \% & NA & $33.6 \%$ & $17.0 \%$ \\
GOAL study, n: & 879 & 863 & 938 \\
Female, \% & $48.2 \%$ & $47.4 \%$ & $52.6 \%$ \\
Age (SD) & $62.90(8.50)$ & $69.05(6.82)$ & $67.83(6.96)$ \\
BMI (SD) & $27.23(4.44)$ & $31.37(5.31)$ & $29.31(5.25)$ \\
Knee gene score (SD) & $6.73(1.67)$ & $6.98(1.70)$ & $6.94(1.73)$ \\
Hip gene score (SD) & $5.93(1.62)$ & $6.10(1.62)$ & $6.24(1.64)$ \\
Hip injury, \% & $1.8 \%$ & $3.4 \%$ & $7.4 \%$ \\
Knee injury, \% & $15.7 \%$ & $32.7 \%$ & $16.5 \%$ \\
\hline
\end{tabular}

BMI, body mass index; GOAL, Genetics of Osteoarthritis and Lifestyle; NA, not applicable; THR, total hip replacement; TKR, total knee replacement. 
Table 3 Age, sex, BMl and genetic risk scores as risk factors for post-traumatic (PT) and non-traumatic (NT) total joint replacement in two study cohorts

\begin{tabular}{|c|c|c|c|c|c|c|c|}
\hline Risk factor & Study cohort & All & p Value & PT & p Value & NT & p Value \\
\hline \multicolumn{8}{|l|}{ TKR: } \\
\hline \multirow[t]{3}{*}{ Age } & GOAL & 1.13 (1.12 to 1.15$)$ & & $1.10(1.08$ to 1.12$)$ & & 1.16 (1.13 to 1.18$)$ & \\
\hline & Nottingham & 1.07 (1.06 to 1.08$)$ & & 1.04 (1.02 to 1.05$)$ & & 1.09 (1.07 to 1.1$)$ & \\
\hline & Summary & 1.09 (1.08 to 1.1$)$ & $4.88 \mathrm{E}-73$ & 1.06 (1.05 to 1.07$)$ & $5.17 \mathrm{E}-20$ & 1.11 (1.10 to 1.12$)$ & $7.05 \mathrm{E}-75$ \\
\hline \multirow[t]{3}{*}{ Sex } & GOAL & $0.99(0.78$ to 1.24$)$ & & 0.61 (0.45 to 0.84$)$ & & 1.41 (1.08 to 1.83$)$ & \\
\hline & Nottingham & $0.76(0.62$ to 0.93$)$ & & 0.49 (0.37 to 0.63$)$ & & $1.00(0.79$ to 1.25$)$ & \\
\hline & Summary & 0.85 (0.73 to 0.99$)$ & 0.039 & 0.53 (0.44 to 0.65$)$ & 1.39E-09 & $1.16(0.97$ to 1.37$)$ & 0.098 \\
\hline \multirow[t]{3}{*}{ BMI } & GOAL & 1.24 (1.21 to 1.27$)$ & & 1.20 (1.16 to 1.25$)$ & & $1.26(1.22$ to 1.29$)$ & \\
\hline & Nottingham & 1.21 (1.18 to 1.24$)$ & & 1.20 (1.16 to 1.23$)$ & & 1.22 (1.19 to 1.25$)$ & \\
\hline & Summary & 1.22 (1.2 to 1.24$)$ & $9.8 \mathrm{E}-106$ & 1.20 (1.17 to 1.23$)$ & $4.2 \mathrm{E}-55$ & 1.24 (1.21 to 1.26$)$ & $1.35 \mathrm{E}-93$ \\
\hline Knee OA & GOAL & 1.08 (1.01 to 1.16$)$ & & 1.14 (1.06 to 1.23$)$ & & 1.07 (1.01 to 1.14$)$ & \\
\hline Risk & Nottingham & 1.09 (1.03 to 1.16$)$ & & $1.10(1.02$ to 1.2$)$ & & 1.10 (1.03 to 1.17$)$ & \\
\hline Genes & Summary & 1.09 (1.04 to 1.14$)$ & 0.00025 & $1.12(1.07 \text { to } 1.19)^{*}$ & $1.82 \mathrm{E}-05$ & $1.08(1.03 \text { to } 1.13)^{*}$ & 0.00063 \\
\hline \multicolumn{8}{|l|}{ THR: } \\
\hline \multirow[t]{3}{*}{ Age } & GOAL & 1.1 (1.08 to 1.11$)$ & & 1.06 (1.03 to 1.09$)$ & & $1.10(1.08$ to 1.11$)$ & \\
\hline & Nottingham & 1.07 (1.05 to 1.08$)$ & & 1.08 (1.05 to 1.11$)$ & & 1.06 (1.05 to 1.08$)$ & \\
\hline & Summary & 1.08 (1.07 to 1.09$)$ & $3.87 \mathrm{E}-57$ & 1.07 (1.05 to 1.09$)$ & $1.11 \mathrm{E}-09$ & 1.08 (1.07 to 1.09$)$ & $1.02 \mathrm{E}-54$ \\
\hline \multirow[t]{3}{*}{ Sex } & GOAL & 1.38 (1.13 to 1.69$)$ & & 1.04 (0.62 to 1.75$)$ & & 1.45 (1.18 to 1.78$)$ & \\
\hline & Nottingham & 1.03 (0.82 to 1.3$)$ & & 1.33 (0.78 to 2.26$)$ & & $0.99(0.78$ to 1.26$)$ & \\
\hline & Summary & 1.22 (1.05 to 1.42$)$ & 0.011 & $1.17(0.81$ to 1.7$)$ & 0.40 & 1.23 (1.05 to 1.44$)$ & 0.0092 \\
\hline \multirow[t]{3}{*}{ BMI } & GOAL & 1.11 (1.09 to 1.14$)$ & & $1.13(1.08$ to 1.19$)$ & & 1.11 (1.09 to 1.14$)$ & \\
\hline & Nottingham & 1.15 (1.12 to 1.18$)$ & & 1.15 (1.08 to 1.22$)$ & & 1.15 (1.12 to 1.19$)$ & \\
\hline & Summary & $1.13(1.11$ to 1.15$)$ & $2.78 \mathrm{E}-42$ & 1.14 (1.1 to 1.18$)$ & $5.71 \mathrm{E}-11$ & $1.13(1.11$ to 1.15$)$ & $4.83 \mathrm{E}-40$ \\
\hline Hip OA & GOAL & $1.13(1.06$ to 1.21$)$ & & $1.06(0.91$ to 1.23$)$ & & $1.14(1.07$ to 1.21$)$ & \\
\hline Risk & Nottingham & 1.08 (1.01 to 1.16$)$ & & $1.08(0.92$ to 1.27$)$ & & 1.08 (1 to 1.16$)$ & \\
\hline Genes & Summary & 1.11 (1.06 to 1.16$)$ & $1.2 \mathrm{E}-05$ & $1.07(0.96 \text { to } 1.19)^{*}$ & 0.24 & $1.11(1.06 \text { to } 1.17)^{*}$ & $1.55 \mathrm{E}-05$ \\
\hline
\end{tabular}

One possible explanation for the lack of differences between PT and primary cases is that the genome-wide association study (GWAS) analyses that identified these variants have not made a distinction between the two types of patients. Given that PT cases constitute a substantial proportion of all knee OA cases, any genetic risk factors identified are likely to be implicated in both types of patients. This is possible since in the case of hip OA the prevalence of hip injury is much lower and the hip genetic risk load among PT THR cases is lower than in primary cases. However the effect of knee risk variants is as strong or even stronger among PT TKR cases indicating that the genes so far identified to influence risk of knee OA play a role in the pathogenesis of severe PT knee OA. However, the OR for hip genes in the PT group is not significantly different from 1 and with the current sample size and the effect size observed the study is not powered to determine if PT THR has a modest genetic component.

Recent research supports the view that acute joint damage that occurs at the time of an injury initiates a sequence of events that can lead to progressive articular surface damage. Determination of the risk factors affecting joint tissues and their respective roles in disease progression is critical to advances in the treatment of PT OA. ${ }^{4}$ Our data indicate that among the risk factors to take into account in PT knee OA are genetic influences.

There are some limitations to this study. Prior injuries were self-reported rather than based on medical records, and may be open to recall bias. Also some of the cases classified as PT OA may actually be 'primary' cases due to the type of injury experienced. Nevertheless, using the current definitions we found strong significant differences in age and gender between PT OA and NT cases, as reported in other studies. ${ }^{3} 4$ Moreover, the questionnaire applied identified a very high risk due to injury for TKR $(\mathrm{OR}=3.27)$ and THR $(\mathrm{OR}=5.08)$ in the case control design. Such risks are much higher than all genetic factors combined. Thus, in spite of the caveats, the population classified as PT based on questionnaire data appears enriched for true PT OA cases. Another limitation is that the results apply to UK populations and may not generalise to other ethnic groups, but the genetic variants used are only those reported in Caucasians as having a role in risk of OA.

In conclusion, PT hip OA cases appear to have a lower genetic risk load than NT cases, whereas PT knee OA cases have at least as high a genetic contribution as NT cases. These data support the perspective of OA as common complex condition and further challenge a clear separation between 'primary' and 'secondary' forms of OA.

Contributors All authors contributed to the study design, data interpretation and the final manuscript. In addition, AMV analysed and interpreted the data and prepared manuscript. SAD and MD evaluated study subjects. AMV and MD supervised the study.

Funding Supported by EC-FP7 programme grant 200800 TREAT-OA and 277849 EurHEALTHAgeing. AstraZeneca UK funded the GOAL study sample and data collection.

Competing interests RAM is an employee of Astrazeneca plc.

Ethics approval the research ethics committees of Nottingham City Hospital and North Nottinghamshire.

Provenance and peer review Not commissioned; externally peer reviewed. 
Open Access This is an Open Access article distributed in accordance with the Creative Commons Attribution Non Commercial (CC BY-NC 3.0) license, which permits others to distribute, remix, adapt, build upon this work non-commercially, and license their derivative works on different terms, provided the original work is properly cited and the use is non-commercial. See: http://creativecommons.org/ licenses/by-nc/3.0/

\section{REFERENCES}

1 Lopez AD, Mathers CD, Ezzati M, et al. Global and regional burden of disease and risk factors, 2001: systematic analysis of population health data. Lancet 2006;367:1747-57.

2 Dieppe PA, Lohmander LS. Pathogenesis and management of pain in osteoarthritis. Lancet 2005:365:965-73.

3 Herrero-Beaumont G, Roman-Blas JA, Castañeda S, et al. Primary osteoarthritis no longer primary: three subsets with distinct etiological, clinical, and therapeutic characteristics. Semin Arthritis Rheum 2009;39:71-80.

4 Anderson DD, Chubinskaya S, Guilak F, et al. Post-traumatic osteoarthritis: improved understanding and opportunities for early intervention. J Orthop Res 2011;29:802-9.

5 Muthuri SG, McWilliams DF, Doherty M, et al. History of knee injuries and knee osteoarthritis: a meta-analysis of observational studies. Osteoarthritis Cartilage 2011;19:1286-93.

6 Brown TD, Johnston RC, Saltzman CL, et al. Posttraumatic osteoarthritis: a first estimate of incidence, prevalence, and burden of disease. J Orthop Trauma 2006;20:739-44
7 Sward P, Kostogiannis I, Neuman P, et al. Differences in the radiological characteristics between post-traumatic and non-traumatic knee osteoarthritis. Scand J Med Sci Sports 2010:20:731-9.

8 Doherty M, Watt I, Dieppe P. Influence of primary generalised osteoarthritis on development of secondary osteoarthritis. Lancet 1983;2:8-11.

9 Englund M, Paradowski PT, Lohmander LS. Association of radiographic hand osteoarthritis with radiographic knee osteoarthritis following meniscectomy. Arthritis Rheum 2004;50:469-75.

10 Valdes AM, Spector TD. The contribution of genes to osteoarthritis. Rheum Dis Clin North Am 2008:34:581-603.

11 Valdes AM, Evangelou E, Kerkhof HJ, et al. The GDF5 rs143383 polymorphism is associated with osteoarthritis of the knee with genome-wide statistical significance. Ann Rheum Dis 2011;70:873-5.

12 Evangelou E, Valdes AM, Kerkhof HJ, et al. Meta-analysis of genome-wide association studies confirms a susceptibility locus for knee osteoarthritis on chromosome 7q22. Ann Rheum Dis 2011;70:349-55.

13 Day-Williams AG, Southam L, Panoutsopoulou K, et al. A variant in MCF2L is associated with osteoarthritis. Am J Hum Genet 2011:89:446-50.

14 arCOGEN Consortium and arCOGEN Collaborators. Identification of new susceptibility loci for osteoarthritis-the arcOGEN study. Lancet 2012:380:815-23.

15 Castaño-Betancourt MC, Cailotto F, Kerkhof HJ, et al. Genome-wide association and functional studies identify the DOT1L gene to be involved in cartilage thickness and hip osteoarthritis. Proc Natl Acad Sci USA 2012:109:8218-23. 